\title{
Numerical simulation of reactive flow in non-equilibrium behind a strong shock wave during re-entry into earth's atmosphere
}

\author{
R. Allouche ${ }^{1, a}$, R. Haoui ${ }^{2}$ and R. Renane ${ }^{3}$ \\ 1 Aeronautical Science Laboratory, Aeronautics Department, S. D. University of Blida, Blida, Algeria \\ 2 University of Science and Technology HB, Alger, Algeria \\ 3 Laboratoire des dynamiques des moteurs et vibroacoustique, UMBB Boumerdes, Algeria
}

Received 26 June 2013, Accepted 1st January 2014

\begin{abstract}
In this paper, we study the phenomena of thermo-chemical imbalance in a reactive monodimensional flow composed of a mixture of ( $79 \%$ nitrogen $\mathrm{N}_{2}$ and $21 \%$ oxygen $\left.\mathrm{O}_{2}\right)$. We are interested in modeling the physicochemical process that may be encountered in hypersonic flows, as vibrational excitation, dissociation and ionization, also the formation of chemical species to higher temperatures behind a detached strong shock. We put a special emphasis on vibrational relaxation model of CVD coupling. At these high temperatures, collisions electrons-atoms become very effective, taking in account the radiation that requires knowledge and modeling of all physicochemical processes (collisional and radiative). The mathematical model of flows at the atmospheric reentry is governed by Euler stationary equations coupled with the chemical kinetics and the radiative transfer equations. Our computational code is based on the finite differences method that used to discretize and resolve the obtained numerical model, where an appropriate mesh is selected in the relaxation zone in order to determine the flow parameters at each grid position
\end{abstract}

Key words: Hypersonic / reactive flow / thermochemical nonequilibrium / vibration / dissociation / ionization / Euler equation / radiative transfer

\section{Introduction}

During the phase of hypersonic reentry of a space vehicle, the air is composed of diatomic species $\left(\mathrm{O}_{2}\right.$ and $\mathrm{N}_{2}$ ). A high kinetic energy causes thermal phenomena in the layer of shock. The sudden increase in temperature provokes the start of physicochemical processes, such as vibrational excitation, dissociation and ionization of molecules. These phenomena related to these conditions lead to a state of thermochemical imbalance and emit an important radiation which contributes significantly to the heating of the wall. A very high temperature plasma is formed from a mixture of many species: $\mathrm{O}, \mathrm{N}, \mathrm{NO}, \mathrm{O}_{2}$, $\mathrm{N}_{2}, \mathrm{O}^{+}, \mathrm{N}^{+}, \mathrm{NO}^{+}, \mathrm{O}_{2}^{+}, \mathrm{N}_{2}^{+}$, and $\mathrm{e}^{-}$[1]. In this simulation we assume that the flow is hypersonic monodimensional, reactive, non-viscous and chemical nonequilibrium behind a strong shock detached taking into account endothermic phenomena which appear in an area called range of relaxation $[2,3]$, with a gradual decrease in temperature up to the chemical equilibrium (see Fig. 1).

${ }^{a}$ Corresponding author: r.allouche@yahoo.fr

\section{Mathematical model}

The mathematical model used to simulate the physical problem is based on the numerical solution of the Euler equations coupled with the chemical kinetics equations. The finite differences method with a progressive scheme is used for discretization of these differential equations. Adequate mesh is selected in the relaxation area in order to determine the flow at each point. To calculate the starting point we use the Rankine-Hugoniot relations which provide the flow properties behind the normal shock according the Mach number. These equations written in a coordinate system related to the shock wave traveling at constant speed can be put in the following form:

$$
\frac{\mathrm{d} \vec{F}(\omega)}{\mathrm{d} x}=\vec{\Omega}(\omega)
$$

where, the vectors $\vec{F}$ and $\vec{\Omega}$ represent the conservative flow and source terms respectively. These vectors are 


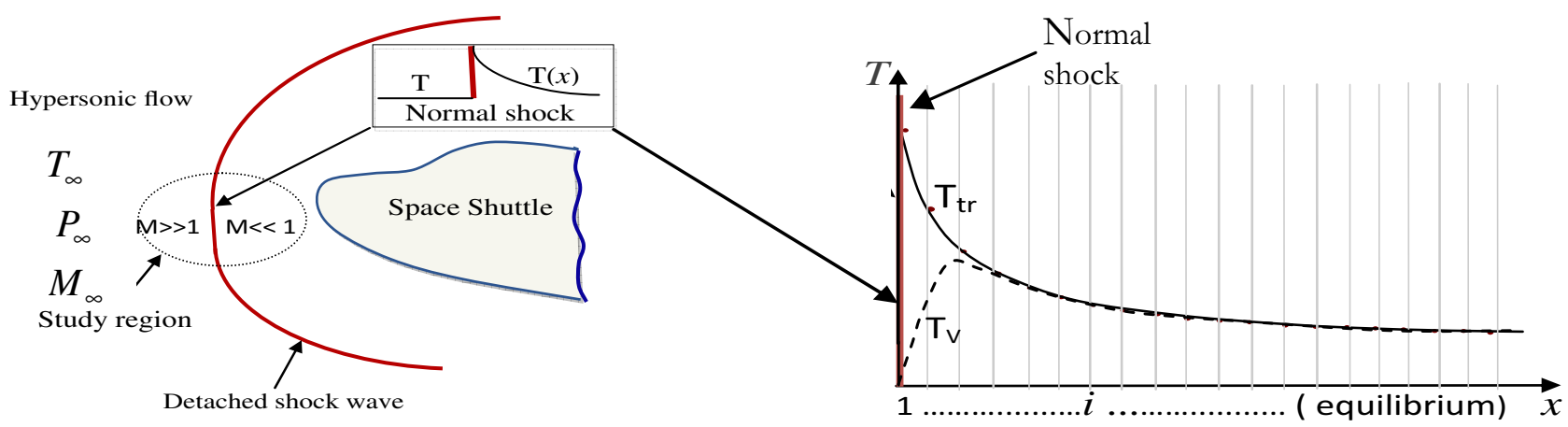

Fig. 1. Variation of thermodynamic parameters behind a normal shock in a hypersonic flow where: $T_{\infty}, P_{\infty}$ and $M_{\infty}$ are respectively the temperature, pressure and velocity before the shock. $T_{\mathrm{tr}}, T_{\mathrm{v}}$ and $M$ : are respectively the translational and vibrational temperature and Mach number behind shock.

expressed as follows:

$$
\begin{aligned}
& F(\omega)=\left\{\begin{array}{c}
\rho u \\
P+\rho u^{2} \\
u(\rho E+P)+q^{\mathrm{rad}} \\
\rho_{s} u \\
\rho_{s} e_{\mathrm{v}, s} u \\
I_{\lambda}
\end{array}\right\} \\
& \Omega(\omega)=\left\{\begin{array}{c}
0 \\
0 \\
0 \\
\omega_{\mathrm{c} s} \\
\omega_{\mathrm{v}, s}+\omega_{\mathrm{cs}} e_{\mathrm{v}, s} \\
e_{\lambda}-I_{\lambda} k_{\lambda}
\end{array}\right\}
\end{aligned}
$$

$u$ and $\rho$ are respectively the velocity and the density of flow, $e_{\mathrm{v} s}$ is the vibrational energy of diatomic species, $\omega_{\mathrm{c} s}$ is the source term of chemical exchange $\omega_{\mathrm{v} s}$ is the source term of production of vibration. $I_{\lambda}$ is the spectral intensity, $\varepsilon_{\lambda}$ and $k_{\lambda}$ are the emission and the absorption coefficients, $\lambda$ is the wavelength. $q^{\mathrm{rad}}$ is the radiative flux, $s$ is the species indication. The energy per unit of mass $E$ is such as:

$E=\sum_{s} Y_{s} \cdot C_{\mathrm{vtr}, s} T+\sum_{\text {diatom }} Y_{s} e_{\mathrm{v}, s}+\sum_{\text {atom }+ \text { ion }} Y_{s} h_{f, s}^{0}+\frac{1}{2}|\vec{u}|^{2}$

where $h_{f, s}^{0}$ is the enthalpy of formation of the species $s$ and is detailed in Table $3, Y_{s}$ is species mass fraction.

The equation of state is given by

$$
P=\sum_{s \neq \mathrm{e}} \frac{\rho_{s}}{M_{s}} R T+\frac{\rho_{\mathrm{e}}}{M_{\mathrm{e}}} R T_{\mathrm{e}}
$$

At the thermal equilibrium and according to Panesi et al. and Thierry et al. $[4,5]$, it is assumed that $T_{\mathrm{e}}=T_{\mathrm{v} \mathrm{N}}$.

$T, T_{\mathrm{e}}$ and $T_{\mathrm{v} \mathrm{N}_{2}}$ are respectively the translational, electronics and vibrational temperatures.

$M_{s}$ and $M_{\mathrm{e}}$ are respectively the molar mass of species $s$ and electron e.

The relaxation equation of chemical species can be written [6]:

$$
\frac{\mathrm{d}\left(\rho_{s} u\right)}{\mathrm{d} x}=\omega_{\mathrm{c} s}
$$

\subsection{Chemical model}

The elementary reactions mechanism, governing the species in high-temperature air, deals with (33) dissociation reactions, (9) exchange reactions, (3) associative ionization reactions and (2) electron impact ionization reactions and is reported in Table 1, known as Park model [1].

At any position in the reactive flow the net chemical reaction rate of species is given by the sum of the rates of the individual reactions $[6,7]$.

$$
\sum_{s=1}^{11} \nu_{s, r}^{\prime} A_{s} \underset{K_{\mathrm{b}, r}}{\stackrel{K_{f, r}}{\Leftrightarrow}} \sum_{s=1}^{11} \nu_{s, r}^{\prime \prime} A_{s}
$$

$A_{s}$ represents any one of the 11 species, and $v_{r, s}^{\prime}, v_{r, s}^{\prime \prime}$ are the stoichiometric mole numbers of the reactants and products of species $s$, respectively, for each chemical reaction $(r)$.

Both forward and backward reaction rates are represented by $K_{f, r}$ and $K_{\mathrm{b}, r}$. The empirically expression for the forward reaction rate $K_{f, r}$ may be written as:

$$
K_{f, r}=A T^{n} \exp \left(-\theta_{\mathrm{d}} / T\right)
$$

where $\theta_{d}$ is the characteristic temperature of dissociation for the $s$ molecule and the constants $A$ and $n$ are given by Table 1 .

For the backward reaction rate, $K_{\mathrm{b}, \mathrm{r}}$, is function of the equilibrium constant $K_{\text {eq }}$

$$
K_{\mathrm{b}, r}=\frac{K_{f, r}}{K_{\mathrm{eq}}}
$$

The equilibrium constant of the chemical reaction is given like a polynomial of the fourth degree

$$
\begin{aligned}
K_{\text {eq }} & =\exp \left(C_{0}+C_{1} Z+C_{2} Z^{2}+C_{3} Z^{3}+C_{4} Z^{4}\right) \\
Z & =\frac{10000}{T}
\end{aligned}
$$

Coefficients $C_{0}, C_{2}, C_{3}$ and $C_{4}$ are provided for each reaction by Gardiner model [8] and reported in Table 2. 
Table 1. Reaction rate parameters in equation (6), Park model [1].

\begin{tabular}{|c|c|c|c|c|c|}
\hline Reactions & & Catalyst $(m)$ & $A$ & $n$ & $\theta_{\mathrm{d}, s}$ \\
\hline \multicolumn{6}{|l|}{ Dissociation } \\
\hline \multirow[t]{3}{*}{$r=1$ to 11} & $\mathrm{O}_{2}+m \Leftrightarrow 2 \mathrm{O}+m$ & $\left(m=\mathrm{O}, \mathrm{N}, \mathrm{O}^{+}, \mathrm{N}^{+}\right)$ & $8.25 \mathrm{E}+19$ & -1.00 & 59500 \\
\hline & & $\left(m=\mathrm{O}_{2}, \mathrm{~N}_{2}, \mathrm{NO}, \mathrm{O}_{2}^{+}, \mathrm{N}_{2}^{+}, \mathrm{NO}^{+}\right)$ & $2.75 \mathrm{E}+19$ & & \\
\hline & & $\left(m=\mathrm{e}^{-}\right)$ & $1.32 \mathrm{E}+22$ & & \\
\hline \multirow[t]{3}{*}{$r=12$ to 22} & $\mathrm{~N}_{2}+m \Leftrightarrow 2 \mathrm{~N}+m$ & $\left(m=\mathrm{O}, \mathrm{N}, \mathrm{O}^{+}, \mathrm{N}^{+}\right)$ & $1.11 \mathrm{E}+22$ & -1.60 & 113200 \\
\hline & & $\left(m=\mathrm{O}_{2}, \mathrm{~N}_{2}, \mathrm{NO}, \mathrm{O}_{2}^{+}, \mathrm{N}_{2}^{+}, \mathrm{NO}^{+}\right)$ & $3.70 \mathrm{E}+21$ & & \\
\hline & & $\left(m=\mathrm{e}^{-}\right)$ & $1.11 \mathrm{E}+24$ & & \\
\hline \multirow[t]{3}{*}{$r=23$ to 33} & $\mathrm{NO}+m \Leftrightarrow \mathrm{N}+\mathrm{O} m$ & $\left(m=\mathrm{O}, \mathrm{N}, \mathrm{O}^{+}, \mathrm{N}^{+}\right)$ & $4.60 \mathrm{E}+17$ & -0.50 & 75500 \\
\hline & & $\left(m=\mathrm{O}_{2}, \mathrm{~N}_{2}, \mathrm{NO}, \mathrm{O}_{2}^{+}, \mathrm{N}_{2}^{+}, \mathrm{NO}^{+}\right)$ & $2.30 \mathrm{E}+17$ & & \\
\hline & & $\left(m=\mathrm{e}^{-}\right)$ & $7.36 \mathrm{E}+19$ & & \\
\hline \multicolumn{6}{|c|}{ Exchange reactions } \\
\hline$r=34$ & $\mathrm{~N}_{2}+\mathrm{O} \Leftrightarrow \mathrm{NO}+\mathrm{N}$ & & $3.18 \mathrm{E}+13$ & 0.10 & 37700 \\
\hline$r=35$ & $\mathrm{NO}+\mathrm{O} \Leftrightarrow \mathrm{O}_{2}+\mathrm{N}$ & & $2.16 \mathrm{E}+08$ & 1.29 & 19220 \\
\hline$r=36$ & $\mathrm{O}+\mathrm{O}_{2}^{+} \Leftrightarrow \mathrm{O}_{2}+\mathrm{O}^{+}$ & & $6.85 \mathrm{E}+13$ & -0.52 & 18600 \\
\hline$r=37$ & $\mathrm{~N}_{2}+\mathrm{N}^{+} \Leftrightarrow \mathrm{N}+\mathrm{N}_{2}^{+}$ & & $9.85 \mathrm{E}+12$ & -0.18 & 12100 \\
\hline$r=38$ & $\mathrm{O}+\mathrm{NO}^{+} \Leftrightarrow \mathrm{NO}+\mathrm{O}^{+}$ & & $2.75 \mathrm{E}+13$ & 0.01 & 51000 \\
\hline$r=39$ & $\mathrm{~N}_{2}+\mathrm{O}^{+} \Leftrightarrow \mathrm{O}+\mathrm{N}_{2}^{+}$ & & $6.33 \mathrm{E}+13$ & -0.21 & 22200 \\
\hline$r=40$ & $\mathrm{~N}+\mathrm{NO}^{+} \Leftrightarrow \mathrm{NO}+\mathrm{N}^{+}$ & & $2.21 \mathrm{E}+15$ & -0.02 & 61100 \\
\hline$r=41$ & $\mathrm{O}_{2}+\mathrm{NO}^{+} \Leftrightarrow \mathrm{NO}+\mathrm{O}_{2}^{+}$ & & $1.03 \mathrm{E}+16$ & -0.17 & 32400 \\
\hline$r=42$ & $\mathrm{~N}+\mathrm{NO}^{+} \Leftrightarrow \mathrm{O}+\mathrm{N}_{2}^{+}$ & & $1.70 \mathrm{E}+13$ & 0.40 & 35500 \\
\hline \multicolumn{6}{|c|}{ Associative ionization } \\
\hline$r=43$ & $\mathrm{O}+\mathrm{N} \Leftrightarrow \mathrm{NO}^{+}+\mathrm{e}^{-}$ & & $1.53 \mathrm{E}+11$ & -0.37 & 32000 \\
\hline$r=44$ & $\mathrm{O}+\mathrm{O} \Leftrightarrow \mathrm{O}_{2}^{+}+\mathrm{e}^{-}$ & & $3.85 \mathrm{E}+11$ & 0.49 & 80600 \\
\hline$r=45$ & $\mathrm{~N}+\mathrm{N} \Leftrightarrow \mathrm{N}_{2}^{+}+\mathrm{e}^{-}$ & & $1.79 \mathrm{E}+11$ & 0.77 & 67500 \\
\hline \multicolumn{6}{|c|}{ Electron impact ionization } \\
\hline$r=46$ & $\mathrm{O}+\mathrm{e}^{-} \Leftrightarrow \mathrm{O}^{+}+\mathrm{e}^{-}+\mathrm{e}^{-}$ & & $3.90 \mathrm{E}+33$ & -3.78 & 158500 \\
\hline$r=47$ & $\mathrm{~N}+\mathrm{e}^{-} \Leftrightarrow \mathrm{N}^{+}+\mathrm{e}^{-}+\mathrm{e}^{-}$ & & $2.50 \mathrm{E}+34$ & -3.82 & 168600 \\
\hline
\end{tabular}

Table 2. Equilibrium constant coefficients of the 47 reactions.

\begin{tabular}{lccccc}
\hline Reactions & $C_{0}$ & $C_{1}$ & $C_{2}$ & $C_{3}$ & $C_{4}$ \\
\hline$r=1$ à 11 & 1.335 & -4.127 & -0.616 & 0.096 & -0.005 \\
$r=12$ à 22 & 3.898 & -12.611 & 0.683 & -0.118 & 0.006 \\
$r=22$ à 33 & 1.549 & -7.784 & 0.228 & -0.043 & 0.002 \\
$r=34$ & 2.349 & -4.828 & 0.455 & -0.075 & 0.004 \\
$r=35$ & 0.215 & -3.657 & 0.843 & -0.136 & 0.007 \\
$r=36$ & -0.411 & -1.998 & -0.002 & 0.005 & 0.000 \\
$r=37$ & 1.963 & -3.116 & 0.692 & -0.103 & 0.005 \\
$r=38$ & 1.705 & -6.223 & 0.522 & -0.090 & 0.005 \\
$r=39$ & 2.391 & -2.443 & -0.080 & 0.027 & -0.002 \\
$r=40$ & 2.132 & -5.550 & -0.249 & 0.041 & -0.002 \\
$r=41$ & 2.115 & -4.225 & 0.524 & -0.095 & 0.005 \\
$r=42$ & 1.746 & -3.838 & -0.013 & 0.013 & -0.001 \\
$r=43$ & -6.234 & -5.536 & 0.494 & -0.058 & 0.003 \\
$r=44$ & -3.904 & -13.418 & 1.861 & -0.288 & 0.015 \\
$r=45$ & -4.488 & -9.374 & 0.481 & -0.044 & 0.002 \\
$r=46$ & -2.980 & -19.534 & 1.244 & -0.190 & 0.010 \\
$r=47$ & -2.553 & -18.870 & 0.472 & -0.060 & 0.003 \\
\hline
\end{tabular}


Table 3. Enthalpy of formation and characteristic temperature of vibration [12].

\begin{tabular}{cccc}
\hline Species & $M_{s}$, g.mol & $\theta_{\text {vib }, s}, k$ & $h_{f}^{\circ},{\mathrm{J} . \mathrm{kg}^{-1}}^{-1}$ \\
\hline $\mathrm{N}_{2}$ & 28 & 3390 & 0. \\
$\mathrm{O}_{2}$ & 32 & 2270 & 0. \\
$\mathrm{NO}$ & 30 & 2743 & 2991594.1 \\
$\mathrm{~N}$ & 14 & - & 33590858.0 \\
$\mathrm{O}$ & 16 & - & 15405691.9 \\
$\mathrm{~N}_{2}^{+}$ & 28 & 3180 & 53702218.9 \\
$\mathrm{O}_{2}^{+}$ & 32 & 2745 & 36405576.6 \\
$\mathrm{NO}^{+}$ & 30 & 3425 & 32834800.0 \\
$\mathrm{~N}^{+}$ & 14 & - & 133828527.9 \\
$\mathrm{O}^{+}$ & 16 & - & 97569090.0 \\
$\mathrm{e}^{-}$ & $5.486 \times 10^{-4}$ & - & 0. \\
\hline \multicolumn{4}{r}{}
\end{tabular}

The source term of the chemical equation of evolution of the species $\mathrm{s}$ is given provided through [9].

$$
\begin{aligned}
\omega_{\mathrm{c} s} & =M_{s} \sum_{r=1}^{47}\left(\nu_{s, r}^{\prime \prime}-\nu_{s, r}^{\prime}\right) J_{r} \\
J_{r} & =K_{f, r} \prod_{s=1}^{11}\left[\frac{\rho_{s}}{M_{s}}\right]^{\nu_{s, r}^{\prime}}-K_{\mathrm{b}, r} \prod_{s=1}^{11}\left[\frac{\rho_{s}}{M_{s}}\right]^{\nu_{s, r}^{\prime \prime}}
\end{aligned}
$$

The vibrational relaxation equation of a molecule is written:

$$
\begin{aligned}
\frac{\mathrm{d}\left(\rho_{s} e_{\mathrm{v}, s} u\right)}{\mathrm{d} x} & =\omega_{\mathrm{c} s} e_{\mathrm{v}, s}+\omega_{\mathrm{v} s} \\
\omega_{\mathrm{v} s} & =\frac{e_{\mathrm{v} s}(T)-e_{\mathrm{v} s}^{\mathrm{eq}}}{\tau_{s}} f_{s}+e_{\mathrm{v} s}^{\mathrm{eq}} \omega_{\mathrm{cs}}
\end{aligned}
$$

$f_{s}, \tau_{s}$ are respectively correction factor of Park and characteristic time of vibration of species.

The equilibrium vibrational energy of molecules is given by Brun [10]:

$$
e_{\mathrm{v} s}^{\mathrm{eq}}=\frac{R \theta_{\mathrm{vib}, s}}{\exp \left(\frac{\theta_{\mathrm{vib}, s}}{T}\right)-1}
$$

The characteristic temperatures of vibration $\theta_{\mathrm{vib}, s}$ of diatomic molecule are given by Table 3 .

\subsection{Coupled vibration dissociation (CVD)}

The effects of vibration on the chemistry exhibited by Treanor and Marrone [7,11], modify the forward reaction rate $K_{f, r}$, and the new constants $K_{f\left(T, T_{\nu}\right)}$ become:

$$
K_{f\left(T, T_{\nu}\right)}=A\left(T_{a}\right)^{n} \exp \left(-\theta_{d} / T_{a}\right)
$$

where $T_{a}=\left(T^{q} T_{\mathrm{v}}^{1-q}\right)$ is the fictive temperature proposed by Park and $q=0.7$ is the correction coefficient.

The coupling coefficient is given by equation $(16)[8,12]$ :

$$
\nu_{\left(T, T_{\mathrm{v}}\right)}=\frac{K_{f,\left(T, T_{\mathrm{v}}\right)}}{K_{f, T}}=\left(T^{q-1} T_{\mathrm{v}}^{1-q}\right)^{n} \frac{\exp \left(-\theta_{d} / T_{a}\right)}{\exp \left(-\theta_{d} / T\right)}
$$

\subsection{Radiative transfer equation (RTE)}

The simplified mathematical formulation of the radiative transfer equation is given by Soubrie [12]:

$$
\frac{\mathrm{d} I_{\lambda}(x, u)}{\mathrm{d} x}=\varepsilon_{\lambda}(x)-k_{\lambda}(x) I_{\lambda}(x, u)
$$

The radiative flux is obtained by integration of the spectral intensity of all wavelengths, and all possible directions [13]:

$$
q^{\mathrm{rad}}(x)=k_{\lambda}(x) \rho \int_{0}^{\infty} \int_{0}^{4 \pi} I_{\lambda}(x, u)\|\vec{u}\| \mathrm{d} \Omega \mathrm{d} \lambda
$$

\section{Numerical model}

The system of equations of mass conservation, momentum and energy is discretized by the finite difference method as follows:

$$
\left.\begin{array}{rl}
\rho_{i} u_{i} & =\rho_{i+1} u_{i+1} \\
P_{i}+\rho_{i} u_{i}^{2} & =P_{i}+\rho_{i+1} u_{i+1}^{2} \\
C p_{m, i}+\frac{1}{2} u_{i}^{2}+\sum_{\text {atom }+ \text { ion }} Y_{s, i} h_{f, s}^{0}+\sum_{\text {diatom }} Y_{s, i} e_{\mathrm{v} s, i} & +\sum_{\text {ion }} Y_{s, i} q_{i}^{\mathrm{rad}} \\
C p_{m, i+1}+\frac{1}{2} u_{i+1}^{2}+\sum_{\text {atom }+ \text { ion }} Y_{s, i+1} h_{f, s}^{0} \\
+\sum_{\text {diatom }} Y_{s, i+1} e_{\mathrm{v} s, i+1}+\sum_{\text {ion }} Y_{s, i+1} q_{i+1}^{\mathrm{rad}}
\end{array}\right\}
$$

The term $e v_{s}(i+1) s$ is explicitly evaluated using the following equation of vibration energy:

$$
e_{v s, i+1}=e_{v s, i}+\Delta x\left(\frac{1}{u_{i} \rho_{s, i}}\left(\omega_{\mathrm{c} s} e_{\mathrm{v} s, i}+\omega_{\mathrm{v} s}\right)\right)
$$

The term $q^{\mathrm{rad}}(i+1)$ of equation (21) is determined using the radiative flux equation (18). It becomes as follows:

$$
\left\{\begin{array}{l}
I_{\lambda, i+1}=\Delta x\left(\varepsilon_{\lambda, i+1}-k_{\lambda i+1} I_{\lambda, i}\right)+I_{\lambda, i} \\
q_{i+1}^{\mathrm{rad}}=\rho_{i} k_{\lambda, i+1} 4 \pi I_{\lambda, i+1}+q_{i}^{\mathrm{rad}}
\end{array}\right.
$$

For each species $s$, the mass fraction relation between points $i$ and $(i+1)$ is given by:

$$
Y_{s, i+1}=\frac{\Delta x}{\rho_{i} u_{i}} \omega_{\mathrm{c} s}+Y_{s, i} ; s=1,2, \ldots, 11
$$

The equation of state must be checked at each point $i$ of computational domain, it is given by:

$$
\frac{P_{i+1}}{\rho_{i+1}}=r_{m, i+1} T_{i+1}
$$




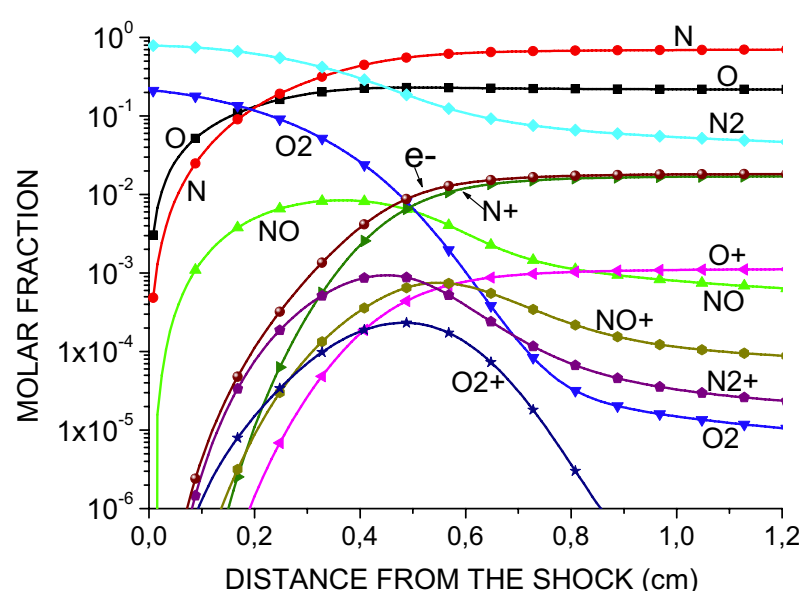

Fig. 2. Evolution of the species mole fraction in the relaxation area; $u_{\infty}=10000 \mathrm{~m} . \mathrm{s}^{-1}, P=10 \mathrm{~Pa}, T_{\infty}=300 \mathrm{~K}$.

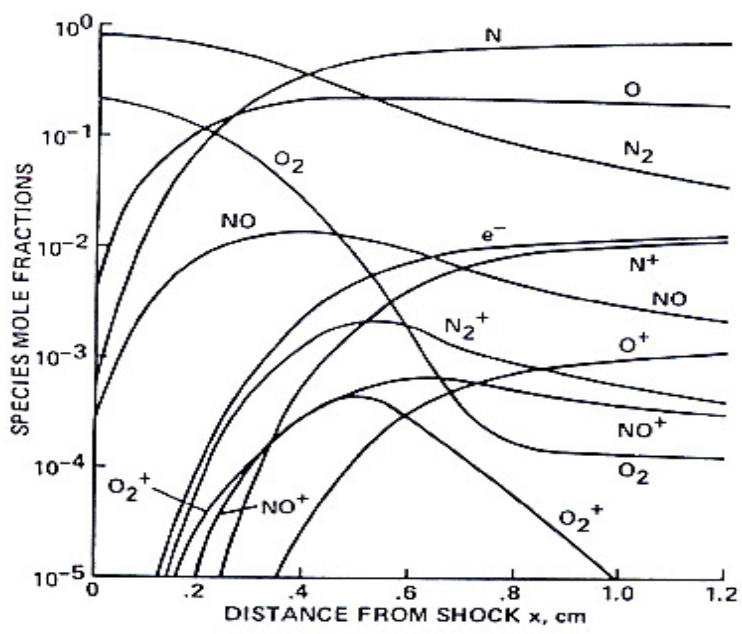

Fig. 3. Species mole fractions calculated by C. Park [3].

\subsection{Algorithmic aspects}

The algorithmic implementation is based on the successive iterations method, where the temperature is iteratively obtained from the total energy expression (21). The pressure is deduced from the equation of state (25). Vibrational temperature $T_{\mathrm{v}}$ of species is determined directly from the vibrational energy equation (22), the speed is calculated from the momentum equation (20) and the concentration of the chemical species is evaluated by equation (24). A convergence test is performed on the temperature prior to a re-evaluation of characteristic variables for each node in the relaxation range until equilibrium.

\section{Results and comments}

Figure 2 illustrates the evolution of the molar concentrations of the eleven species in the relaxation area. Under the effect of the dissociation reactions, the amount of $\left(\mathrm{O}_{2}, \mathrm{~N}_{2}\right)$ decreases from their initial values of $(21 \%, 79 \%)$

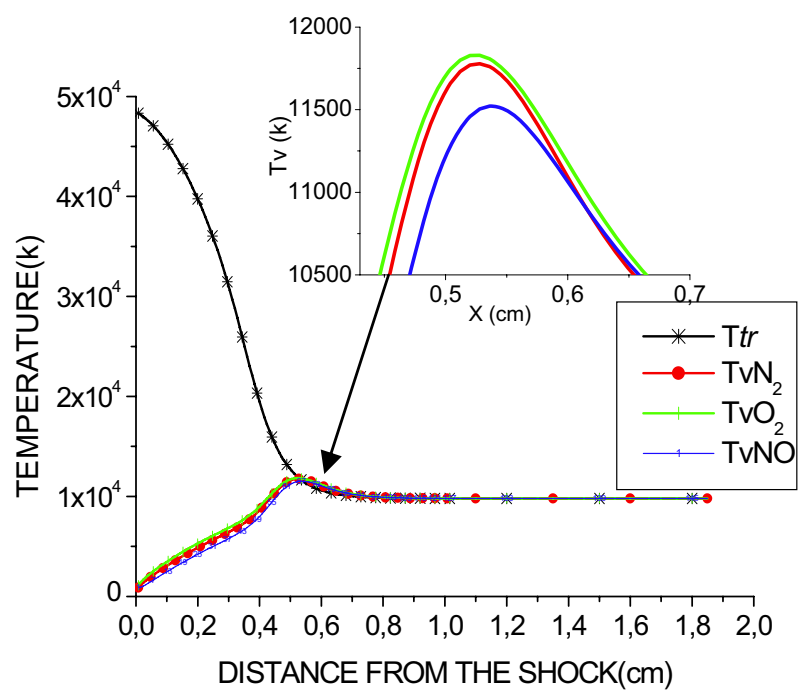

Fig. 4. Calculated temperatures $T_{\mathrm{tr}}$ and $T_{\mathrm{vN} 2}, T_{\mathrm{vO} 2}, T_{\mathrm{vNO}}$ behind shock; $u_{\infty}=10000 \mathrm{~m} . \mathrm{s}^{-1}, P_{\infty}=10 \mathrm{~Pa}, T_{\infty}=300 \mathrm{~K}$.

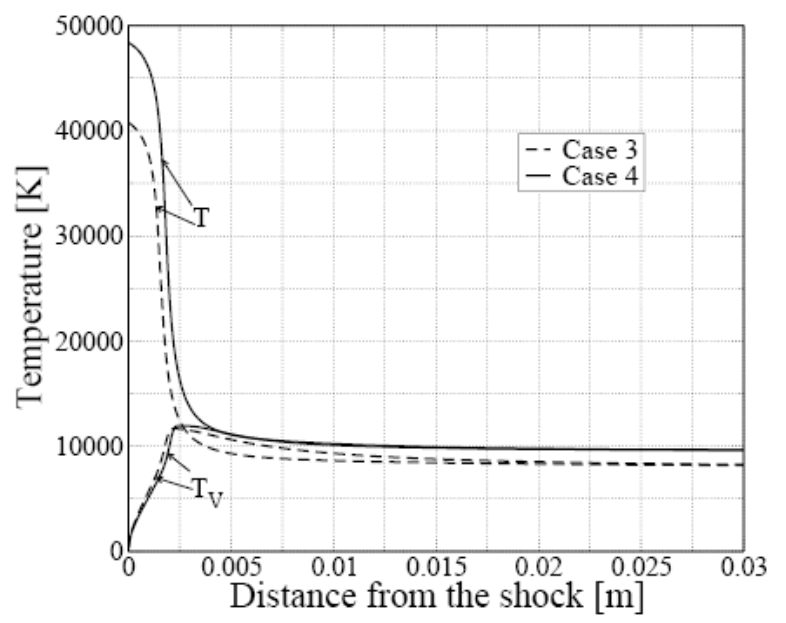

Fig. 5. Temperature profiles calculated by Panesi et al. [4].

to the equilibrium values $(5 \mathrm{E}-3 \%, 0.42 \%)$. Also, we have the formation of $18 \% \mathrm{O}, 60 \% \mathrm{~N}$ and $5.7 \mathrm{E}-2 \% \mathrm{NO}$. As a result of ionization reactions, we have the formation of, $9.2 \%$ of electron, $63 \mathrm{E}-3 \% \mathrm{NO}^{+}, 9 \% \mathrm{~N}^{+}, 2.3 \mathrm{E}-3 \% \mathrm{~N}_{2}^{+}, \mathrm{O}^{+}$ $4.5 \%$ and $2.1 \mathrm{E}-5 \% \mathrm{O}_{2}^{+}$. We note that our results with a chemical model of 47 reactions corroborate the results of Allouche et al. [14] and Park [3] with a model of 31 reactions, an infinitesimal difference is observed at $\mathrm{N}_{2}^{+}$and $\mathrm{NO}^{+}$.

In Figure 4 we represent respectively, the evolution of translational and vibrational temperatures of diatomic molecules. Note that the translational temperature is very important behind the shock, then decreased steadily and rapidly under the effect of endothermic reactions, other hand, a rapid increase in temperature $\left(T v_{\mathrm{O} 2}, T v_{\mathrm{N} 2}\right.$ and $\left.T v_{\mathrm{NO}}\right)$ in the form of bell, and then stabilizes at equilibrium with the temperature of the flow. Good agreement is observed between our results and those of Panesi et al. [4] for similar initial flight conditions. 


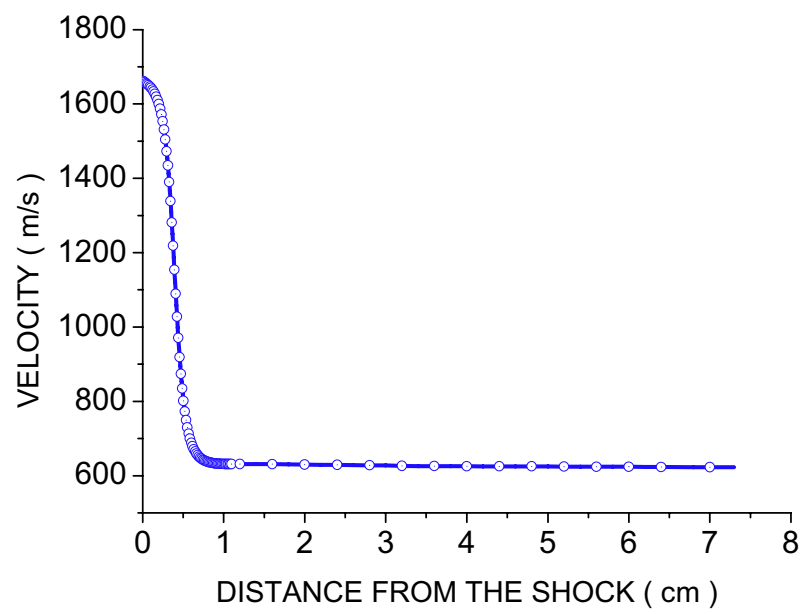

Fig. 6. Calculated velocity behind the shock; $u_{\infty}=$ $10000 \mathrm{~m} . \mathrm{s}^{-1}, \mathrm{P}_{\infty}=10 \mathrm{~Pa}, T_{\infty}=300 \mathrm{~K}$.

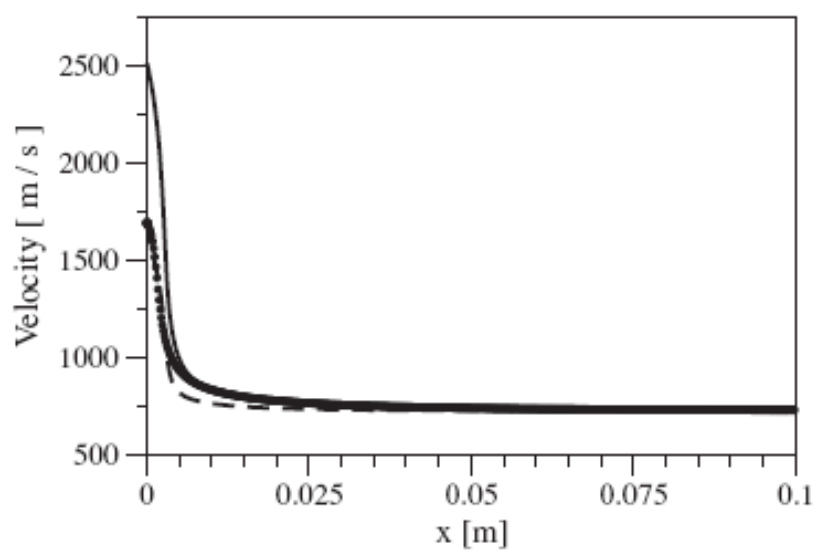

Fig. 7. Velocity profiles behind shock calculated by Magin et al. [5].

Figure 6 illustrates the evolution of velocity behind the shock because, the flow before the strong shock is $10 \mathrm{~km} . \mathrm{s}^{-1}$, it undergoes an sudden deceleration through the shock up to a speed of $1700 \mathrm{~m} . \mathrm{s}^{-1}$. The physicochemical processes which occur under the effect of high temperatures have the endothermic nature, and cause the rapid decrease in speed until equilibrium at a value near $700 \mathrm{~m} . \mathrm{s}^{-1}$. Our results are in good agreement with the work of Magin et al. [5].

Figure 8 shows the evolution of the translational temperature in vibrational and chemical non-equilibrium, with and without radiation in the relaxation area. For speeds above $10 \mathrm{~km} . \mathrm{s}^{-1}$, the radiation contributes significantly; the temperature profile with radiation is below that of without radiation. This advantage is due to the effect of radiation that allows decreasing the temperature of the flow.

Figure 9 illustrates the evolution of radiative fluxes for major species $\left(\mathrm{O}_{2}, \mathrm{~N}_{2}\right.$ and $\left.\mathrm{NO}\right)$ and for minor species $(\mathrm{O}, \mathrm{N})$. We note that the flux emitted by the diatomic species is important compared to the monatomic emitted

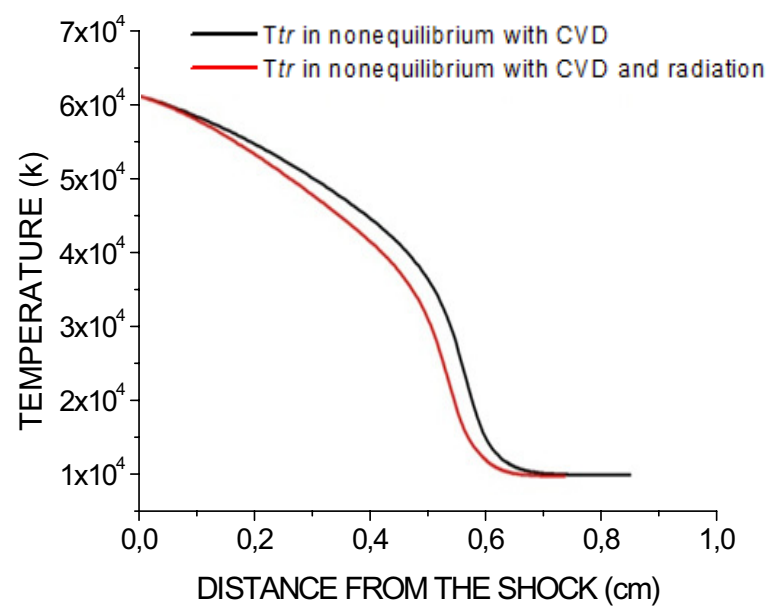

Fig. 8. Temperature profiles calculated for the nonequilibrium case with and without radiation; $u_{\infty}=$ $11360 \mathrm{~m} . \mathrm{s}^{-1}, P_{\infty}=2 \mathrm{~Pa}, T_{\infty}=195 \mathrm{~K}$.

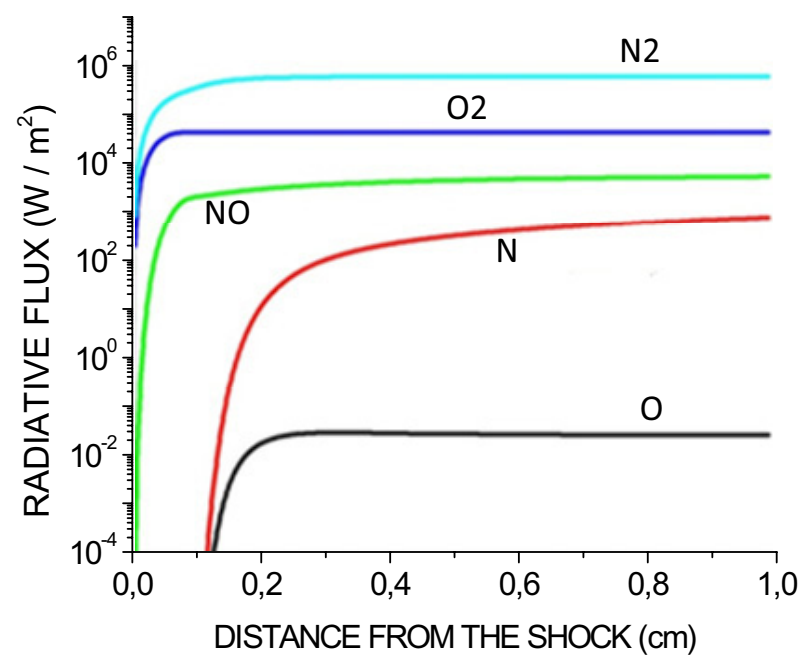

Fig. 9. Evolution of radiative heat fluxes behind the strong shock, $u_{\infty}=11360 \mathrm{~m} . \mathrm{s}^{-1}, P_{\infty}=2 \mathrm{~Pa}, T_{\infty}=195 \mathrm{~K}$.

flux, it comes to the phenomenon of dissociation that promotes the excitation of the diatomic molecules relative to monatomic molecules.

\section{Conclusion}

This work is a contribution for study of the phenomena of thermo-chemical imbalance in a reactive monodimensional flow, which reigns in the atmospheric reentry. The physicochemical process that may be encountered in hypersonic flows, as vibrational excitation, dissociation and ionization at high temperatures behind a detached strong shock, using vibrational relaxation model with CVD coupling is modelized by equations governing the radiative transfer phenomena.

The present four-temperature model assumes that the first temperature $T_{\mathrm{tr}}$ characterizes the translational and 
rotational energies, and temperatures $\left(T_{\mathrm{vO} 2}, T_{\mathrm{vNO}}\right.$ and $T_{\mathrm{vN} 2}=T_{\mathrm{e}}$ ) characterize the molecular vibrational and electron translational energies. This model is more obvious than the two temperature model used by several authors, since it accounts for the limiting post-shock section and diffusive nature of vibrational relaxation at high temperatures. Besides, we used a reaction mechanism of 47 reactions, with a shock velocity of $10 \mathrm{~km} . \mathrm{s}^{-1}$ which is more appropriate with the NASA report [15], which defines the flow regime capsules during atmospheric reentry.

The temperature $T$ is initially about $49000 \mathrm{~K}$ behind the shock wave and decrease monotonically for Parck work [3] until reaches $13152 \mathrm{~K}$, but for the present work, $T$ reaches $9900 \mathrm{~K}$ at equilibrium and coincides with $T_{\mathrm{V}}$ temperature. This difference (less of $3252 \mathrm{~K}$ ) is caused by using a reaction mechanism that contains more endothermic reactions. Also, we have the formation of many species under the effect of the dissociation reactions and many ions as a result of the ionization reactions. These reactions have the endothermic nature. Furthermore, the effect of radiation taken into account in this work contributes to reduce the temperature of flow.

The previously mentioned points have as main objective to reduce quickly the temperature of flow after the shock and reduce the relaxation zone and reach quickly the equilibrium in order to weaken the influence of impact temperature of flow on the wall of space vehicles.

\section{References}

[1] C. Park, On Convergence of Computation of Reacting Flows, Ed. AIAA-85-0247, 1985

[2] R. Allouche, R. Haoui, Ecoulement d'air ionisé en hors équilibre chimique derrière une onde de choc droite, $18^{\text {ème }}$ Congrès Français de Mécanique Grenoble, 2007, pp. 27-31

[3] C. Park, Assessment of Two- Temperature Kinetic Model for Ionizing Air, J. Thermophysics (1989)

[4] M. Panesi, T.E. Magin, A. Bourdon, A. Bultel, O. Chazot, Y. Badou, Collisional-radiative modeling in flow simulations, NATO Research and Technology Organization, 2008
[5] T.E. Magin, M. Panesi, A. Bourdon, R.L. Jaffe, D.W. Schwenke, Coarse-grain model for internal energy excitation and dissociation of molecular nitrogen, Chem. Phys. 398 (2012) 90-95

[6] H.M. Damevin, K. Hoffmann, Numerical Magnetogasdynamics Chemically Reacting Flows, AIAA 2001-2746, 2001

[7] J.M. Lamet, Transferts radiatifs dans les écoulements hypersoniques de rentrée atmosphérique terrestre, Thèse Doctorat (E.M2.C.) UPR 288, CNRS et École Centrale Paris. 21 Septembre 2009

[8] W.C. Gardiner, Combustion chemistry, Springer Verlag, New-York, 1984

[9] L. Dala, Hypersonic Viscous Flows Including NonEquilibrium Real Gas Effects, Manchester School of Engineering Aerospace Division, 1997

[10] R. Brun, Transport et relaxation dans les écoulements gazeux, Masson, 1986

[11] C.E. Treanor, P.V. Marrone, Effect of Dissociation on the Rate of Vibrational Relaxation, Phys. Fluids 5 (1962) $1022-1026$

[12] T. Soubrie, Prise en compte de l'ionisation et du rayonnement dans la modélisation des écoulements de rentrée terrestre et martienne, Thèse Doctorat de SUPAERO, Novembre 2006

[13] A.L. Jaumotte, Chocs et Ondes de Choc, Tome II, Masson et $\mathrm{C}^{\mathrm{ie}}$, Editeurs 120, BD Saint-Germain, Paris, $6^{\mathrm{e}}, 1973$

[14] R. Allouche, R. Haoui, J.D. Parisse, R. Renane, Study of Thermo-Chemical Non-Equilibrium Phenomena behind Strong Shock Waves at Atmospheric Re-entry, AMR 274 (2011)

[15] R.N. Gupta, J.M. Yoss, RA. Thompson, K.P. Lee, A review of reaction rates and thermodynamic and transport properties for an 11-species air model for chemical and thermal nonequilibrium calculations to $30000 \mathrm{~K}$. NASARP-1232, 1990

[16] R. Allouche, R. Haoui, Ionising Air in Thermo and Chemical Nonequilibrium Flow Behind a Plane Shock Wave, 14th AIAA Space Planes and Hypersonic Systems and Technologies Conference, 2006 